\title{
Trabalho, proteção social e desenvolvimento
}

JOSÉ CELSO CARDOSO JR. ${ }^{I}$

\section{Notas introdutórias: trabalho e civilização}

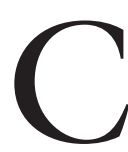

ONSIDERADO por muitos como uma maldição dos deuses (trabalho como penitência) ou simplesmente como um mal necessário (ganhar o sustento com as próprias mãos), o fato é que o Trabalho se converteu, para a humanidade, em elemento central dos processos de organização econômica e da própria vida social.

Historicamente, sobretudo com o advento e quase universalização do modo capitalista de produção, distribuição e acumulação da riqueza social, o trabalho é a fonte de existência e a razão de vida para a imensa maioria dos homens comuns. É condição inescapável de sobrevivência individual e de reprodução familiar e social da espécie humana.

Grosso modo, a razão para tanto decorre, fundamentalmente, do fato de a categoria Trabalho ser, mormente em regime capitalista, a categoria econômica e sociológica chave para garantir, sobretudo em contextos extremamente desiguais e heterogêneos como o brasileiro:

i. Sustento individual ou familiar, além de sociabilidade básica à população, por meio do acesso à renda e à esfera pública que o trabalho propicia;

ii. Sustentação econômica mínima ao PIB, por meio da amplitude e profundidade potenciais do seu mercado consumidor interno; e

iii. Sustentabilidade financeira intertemporal a todo o sistema brasileiro de proteção social, em particular aos sistemas previdenciários públicos, direta ou indiretamente contributivos, pelo peso que as fontes de financiamento direto (ancoradas no trabalho) ou mesmo indireto (regressivamente ancoradas na tributação sobre o consumo, mas legalmente vinculadas ao orçamento da seguridade social) possuem no Brasil.

Desta feita, não poderia ser mais oportuna a escolha do tema Trabalho como mote transversal dos artigos a comporem esta edição da revista Estudos Avançados, do Instituto de Estudos Avançados da Universidade de São Paulo (IEA-USP). Ainda mais se tomando em conta que, em 2013, a senhora Consolidação das Leis do Trabalho (CLT) completou setenta anos de vida e a jovem Constituição Federal de 1988 (CF-88), seus 25 aninhos. Tanto em uma como em outra, o direito ao trabalho digno (ou trabalho decente, conforme a Organização Internacional do Trabalho - OIT), aparece como elemento estruturante da sociedade. 
Não obstante, após todos esses anos de vigência da CLT e da Constituição que estatuiu o trabalho como direito (artigos $6^{\circ}$ e $7^{\circ}$, no capítulo da Ordem Social) e a cobertura previdenciária universal como princípio, entre um terço e quase metade dos trabalhadores brasileiros (a depender dos critérios utilizados para o cálculo) encontra-se ainda sem qualquer acesso a ambos. A melhora dos indicadores relativos ao emprego, observada entre 2003 e 2013, ainda não se traduziu em mudança sensível desse quadro de desproteção social, que resulta, fundamentalmente, do descompasso entre as condições sociolaborais da população e a concepção predominantemente contributiva que ainda ancora os critérios de acesso e o próprio plano de benefícios da Seguridade Social brasileira.

Em 2015, essa situação agravou-se, não apenas em razão da deterioração dos quadros econômico e político, mas, sobretudo, em razão da reorientação conservadora que passou a pautar as diretrizes e ações do segundo governo Dilma. ${ }^{1}$ Em síntese, por razões cujas explicações extrapolam o escopo deste trabalho, a conjuntura brasileira deteriorou-se, colocando dúvidas sobre a continuidade do processo de desenvolvimento em curso desde 2003, no qual os vetores da inclusão social pelo mercado laboral interno, dos investimentos em infraestrutura econômica, social e urbana, capitaneados pelo Programa de Aceleração do Crescimento (PAC) desde 2007, e da exploração de recursos naturais (notadamente o petróleo), eram eixos centrais do modelo. ${ }^{2}$

Mui brevemente, referimo-nos a um conjunto de fatores como:

- A persistência da crise econômica internacional que se arrasta desde 2008;

- A queda dos preços internacionais do petróleo, situação que se vê agravada, no caso brasileiro, por denúncias de corrupção envolvendo contratos superfaturados da Petrobras, a principal empresa estatal nacional a compor o arranjo até aqui exitoso de recuperação de investimentos em infraestrutura no país;

- A sobreposição de crise hídrica e crise energética, afetando justamente a região Sudeste - vale dizer, a mais industrializada e populosa - do Brasil;

- Uma crise política decorrente do acirramento ideológico havido nas últimas eleições presidenciais brasileiras em 2014, e que se desdobra, desde então, em fortes tensões e descrédito intra e entre os poderes Executivo, Legislativo e Judiciário, todos envolvidos em casos de corrupção ativa ou passiva;

- Por fim, mas não menos importante, e sem pretender estender demasiadamente a lista, uma profunda crise de legitimidade e desconfiança sobre os principais meios de comunicação privados do país (televisões, rádios, jornais e revistas, impressos e eletrônicos), os quais vêm assumindo posicionamentos político-ideológicos abertamente oposicionistas ao governo, em particular ao Partido dos Trabalhadores, inclusive com feições golpistas em vários casos. ${ }^{3}$

Tudo somado, trata-se, portanto, de ambiente bastante acirrado de contradições que vem jogando para baixo tanto o nível pretérito de confiança engendrado pelo modelo de crescimento como as expectativas futuras da classe empresarial (nacional e estrangeira) em relação às perspectivas de novos negó- 
cios e sustentação do crescimento econômico. Em suma, podemos resumir a situação dizendo que a convenção de crescimento que ancorou a trajetória exitosa da economia brasileira entre 2007 e 2010 pode ter se esgotado ou aguardando o desfecho dos acontecimentos narrados acima.

Dessa forma, é possível afirmar que, a despeito dos impactos altamente positivos engendrados tanto pela CLT como pela CF-88, a questão social brasileira segue encontrando expressão atual no grande peso representado ainda pelo setor de subsistência no campo e de um igualmente grande setor urbano de pessoas não inseridas nos mundos do trabalho e da proteção pública de maneira minimamente estruturada e regulamentada. ${ }^{4}$

Isso posto, a reversão desse descompasso e das lacunas protetivas que ele enseja é o norte deste artigo. Do ponto de vista técnico, isso é algo que tem se mostrado - pelo menos desde a última década - plenamente factível. Prova disso é que a primeira década do novo milênio, particularmente o período 2003-2013, cumpriu - entre outras - função didática nos embates acadêmico e político brasileiros. Após praticamente 25 anos de dominância ideológica liberal e tentativas - em vários campos da vida social e econômica - de implementação de diretrizes e soluções desregulamentadoras, privatistas e internacionalizantes, com resultados pífios ou nefastos sobre indicadores e variáveis clássicas do comportamento macroeconômico e do mercado de trabalho nacional, houve no mencionado período recente a contestação empírica e teórica da alegada supremacia daquelas formulações.

Embora grande parte dessas não tenha sido plenamente revertida, e considerando ainda a influência benéfica do cenário internacional (sobretudo entre 2000 e 2008 ) para os resultados domésticos favoráveis em termos macroeconômicos e laborais, comprovou-se na prática que o núcleo duro do padrão brasileiro de proteção social, ancorado historicamente no modelo contributivo e no binômio trabalho-proteção social, é altamente dependente - em termos de sua sustentabilidade institucional e financeira - de dinâmica produtiva pujante e virtuosa, praticamente impossível de ser obtida por obra e graça das forças de mercado, tal como vem sendo novamente comprovado pelo pacote de medidas liberalizantes e fiscalistas em curso neste segundo mandato Dilma.

Com isso, sugere-se que as maiores dificuldades, tanto para a efetivação do trabalho como direito, bem como para uma efetiva universalização da proteção social no Brasil, são de outra ordem. A discussão que vem sendo travada entre distintas concepções a respeito da Seguridade Social em geral, e da Previdência Social em particular, é reflexo da disputa entre diferentes setores sociais e econômicos pelos recursos que a ela aportam e/ou dela recebem. E, nesse embate, a correlação de forças tem sido historicamente desfavorável à população trabalhadora. Isso se reforça pelo fato de a Seguridade Social brasileira encontrar-se na estratégica e paradoxal situação de ser, de um lado, espelho da sociedade e do Estado brasileiro; de outro, o principal contraponto a tais iniquidades, e em cuja superação tem papel-chave. ${ }^{5}$ 
Assim, criar as condições políticas necessárias à mudança dessa correlação é algo que só pode ser feito pela própria classe-que-pive-do-trabalho (Antunes, 1999), diretamente ou por meio de seus representantes, ainda que esses, nos dias que correm, estejam encurralados entre seus princípios históricos e as premências do ajuste recessivo em curso, capitaneado e defendido pelo atual governo Dilma como forma - supostamente a única! - de garantir a governabilidade e salvar o próprio mandato presidencial.

\section{Civilização e proteção social}

Neste estudo, parte-se do reconhecimento de que o mundo do trabalho no Brasil é algo mais complexo do que supõem as teorias convencionais sobre o assunto, fato que suscita a necessidade de abordagens analíticas menos reducionistas ao tema em pauta. ${ }^{6}$ Dentre as alternativas existentes, parece-nos adequado começar por distinguir os dois principais vetores de determinação da ocupação no país, cada qual responsável por fatia significativa da ocupação total. São eles:

- Vetor da demanda por força de trabalho: depende de fatores associados ao cálculo econômico privado e/ou a decisões de gasto real dos governos. Em ambos os casos, os postos de trabalho assim forjados costumam tomar as seguintes formas: i) assalariamento direto com carteira, além de militares e estatutários; ii) assalariamento direto, mas sem carteira; e iii) assalariamento indireto ou disfarçado (sem carteira): terceirização, cooperativas, "pejotização" etc.

- Vetor da oferta de força de trabalbo: depende de fatores ligados à sobrevivência individual ou familiar imediata. Esses postos de trabalho tomam, em geral, a forma de: i) trabalhadores autônomos ou por conta própria; ${ }^{7}$ ii) trabalhadores no autoconsumo e/ou na autoprodução, tanto no campo como nas cidades; e iii) trabalhadores não remunerados.

Essa diferenciação é especialmente relevante de se fazer em contextos tais quais o brasileiro, marcado por padrão retardatário e incompleto de desenvolvimento capitalista, onde grassa imensa heterogeneidade da estrutura produtiva (logo, com diferentes padrões de determinação da ocupação) e imensa precarização nas relações e condições de trabalho para a maior parte da população, mesmo aquela inserida em regime de assalariamento típico.

Tal como disposto na Figura 1, pelo lado da oferta de força de trabalho, está a questão de que grande parte da ocupação desde sempre existente no país ter sido gerada por força do excesso de trabalhadores em idade ativa, em comparação com a capacidade de o sistema econômico absorver tal contingente. Pelo lado da demanda por força de trabalho, está a questão de que mesmo a dinâmica "modernizante" aqui instaurada (que envolve tanto a demanda ocupacional privada como a estatal) não se traduz, automática e necessariamente, em postos de trabalhos regulados pelo padrão formal-legal vigente de contratação. 
Figura 1 - Clivagens entre formal e informal para o estudo do mercado do trabalho no Brasil

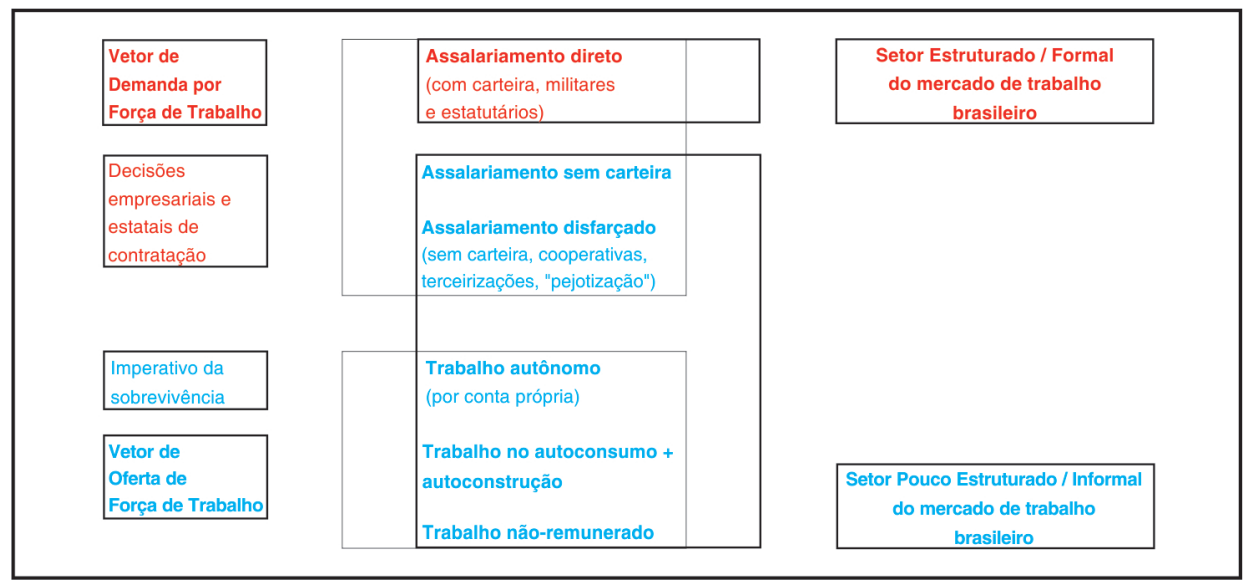

Fonte: Elaboração própria.

Como consequência, o capitalismo aqui instalado e a atuação regulatória do Estado no campo trabalhista não lograram universalizar o fenômeno do assalariamento formal do trabalho, tornando incompleto o "processo civilizatório" de um capitalismo minimamente organizado, tal qual levado a cabo na experiência de alguns países ocidentais. Desse modo, a inserção das pessoas no mundo da proteção social pela via do trabalho, se já não havia sido a regra para cerca de metade da população ocupada até 1980, deixou de ser aspiração confiável ao longo dos vários anos subsequentes de crise econômica, estatal e social no Brasil. Dos movimentos recentes de recuperação do emprego formal e de aumento da filiação previdenciária, registrados ao longo da década 2003 a 2013, não se pode dizer que sejam fenômenos inscritos numa trajetória já virtuosa de longo prazo, presos que estão a ambientes econômicos e institucionais ainda cheios de riscos e incertezas. Prova disso são as oscilações dos grandes agregados macroeconômicos, desde 2008, por conta da crise internacional ainda em curso, e desde 2014, pelo aprofundamento da crise interna da economia brasileira. ${ }^{8}$

\section{O peso e o papel da Constituição Federal de 1988}

Como se sabe, a intervenção do Estado no campo social mudou de patamar após a implementação dos dispositivos constitucionais relativos à ampliação de direitos ligados à previdência e assistência social, saúde, ensino fundamental, trabalho, função social da propriedade, apenas para ficar nos mais evidentes.

Daí a importância de se produzir um mapeamento não exatamente das condições de vida em geral da população, mas especificamente das suas condições de (des) proteção social - fenômeno aqui entendido tão somente a partir da capacidade de cobertura social propiciada por um conjunto predefinido 
de políticas sociais - políticas que transferem renda no âmbito da previdência social, assistência social e políticas de emprego, trabalho e renda, conforme Quadro 1.

Quadro 1 - Os mundos da proteção e da desproteção social segundo a condição de atividade da população em idade ativa e inativa

\begin{tabular}{l|l|l}
\hline & \multicolumn{1}{|c|}{ MUNDO DO TRABALHO } & \multicolumn{1}{c}{ MUNDO DA INATIVIDADE } \\
\hline & $\begin{array}{l}\text { 1. ocupação protegida auto- } \\
\text { financiável: RGPS* urbano + RJU*; } \\
\text { 2. auto-ocupação protegida auto- } \\
\text { financiável; } \\
\text { 3. segurados especiais: RGPS } \\
\text { rural parcial e indiretamente } \\
\text { financiável; } \\
\text { 4. proteção temporária: seguro- } \\
\text { desemprego. }\end{array}$ & $\begin{array}{l}\text { 5. cobertura previdenciária: } \\
\text { RPGS rural + urbano + RJU; } \\
\text { 6. cobertura assistencial } \\
\text { estatal + filantrópica; } \\
\text { 7. cobertura previdenciária } \\
\text { privada. }\end{array}$ \\
\hline \multirow{2}{*}{ SESPROTEÇÃO } & $\begin{array}{l}\text { 1. ocupação protegida auto- } \\
\text { financiável: RGPS urbano + RJU; } \\
\text { 2. auto-ocupação protegida auto- } \\
\text { financiável; } \\
\text { 3. segurados especiais: RGPS } \\
\text { rural parcial e indiretamente } \\
\text { financiável; } \\
\text { 4. proteção temporária: seguro- } \\
\text { desemprego. }\end{array}$ & $\begin{array}{l}\text { 4. ausência de cobertura } \\
\text { previdenciária (estatal ou } \\
\text { privada); } \\
\text { 5. ausência de cobertura } \\
\text { assistencial (estatal ou } \\
\text { filantrópica). }\end{array}$ \\
\hline
\end{tabular}

Fonte: IBGE, PNAD: para categorias de "posição na ocupação". Elaboração própria.

* Regime Geral de Previdência Social.

** Regime Jurídico Único.

O substrato teórico-metodológico para entender a definição de (des) proteção restrita é a constatação de que toda sociedade, em cada momento do tempo, aciona e combina de forma diferenciada (seja voluntária ou involuntariamente) quatro grandes segmentos sociais, claramente discerníveis, na tarefa indispensável de gerar proteção social ao seu corpo populacional, ou mais modernamente, à sua comunidade de famílias e cidadãos (Esping-Andersen, 2000), conforme Quadro 2.

Os quatro grandes segmentos sociais são: o Estado, o Mercado, as Famílias e as Comunidades Civis de atuação no espaço nacional, as quais incluem não só a atuação das comunidades difusas e pouco institucionalizadas, mas ainda a atuação do chamado setor público não estatal ou terceiro setor. ${ }^{9}$ No caso brasileiro, sobretudo após o marco constitucional de 1988, haveria certa divisão de responsabilidades ou de atribuições para aqueles quatro grandes segmentos sociais. 
Quadro 2 - Grau de proteção social, por classes sociais e entes provedores - Brasil

\begin{tabular}{l|c|c|c}
\hline & Classes Altas & Classes Médias & Classes Baixas \\
\hline Estado & Médio & Alto & Alto \\
\hline Mercado & Alto & Médio & Baixo \\
\hline Famílias & Médio & Alto & Alto \\
\hline Sociedade Civil & Baixo & Baixo & Médio \\
\hline
\end{tabular}

Fonte: Cardoso Jr. (2013a). Elaboração própria.

Em linhas gerais, poderíamos dizer que a proteção social, para as classes superiores na pirâmide distributiva brasileira, dependeria fortemente do seu acesso aos mercados privados de educação (sobretudo nos níveis fundamental e médio), saúde e previdência complementar, ${ }^{10}$ ainda que o Estado compareça, em alguma medida, como provedor de determinados bens e serviços, sobretudo na educação superior, certas especialidades da saúde, teto de remuneração da previdência pública etc.

Já os estratos médios da pirâmide social brasileira estariam sendo majoritariamente cobertos pelas políticas públicas do Estado, sobretudo em educação, saúde, previdência e segurança pública, com alta participação também das próprias redes familiares na provisão de parte não desprezível de bens e serviços nessas mesmas áreas citadas. Para esses estratos, o Mercado apareceria de modo mediano na provisão de bens e serviços.

Por fim, as classes sociais inferiores da pirâmide distributiva brasileira estariam a depender, majoritariamente, do Estado e das Famílias, sendo baixa a participação do Mercado e média a da Sociedade Civil organizada na provisão de bens e serviços de proteção social a esses segmentos.

Com as considerações anteriores em mente, torna-se razoável afirmar, para o caso brasileiro atual, que:

i. A centralidade da proteção social, em uma sociedade capitalista razoavelmente desenvolvida, ancora-se sobre políticas e programas de transferência e garantia de renda, de modo que as áreas previdenciária, assistencial e de emprego, trabalho e renda convertem-se em eixo central da proteção social. Importante notar que este aspecto independe da forma de financiamento da proteção social, vale dizer: de se o modelo é liberal-residual (como nos países anglo-saxões), meritocrático-contributivo (como nos países europeus continentais), social democrata-universalista (como nos países europeus nórdicos) ou familístico (como nos países europeus meridionais). Em todos os casos, o eixo central da proteção social ancora-se sobre garantias e transferências de renda por meio de políticas previdenciárias, assistenciais e de emprego, trabalho e renda;

ii. Num contexto socioeconômico como o brasileiro, em que o patamar de renda domiciliar per capita é reduzido e sua distribuição muito desigual, o Esta- 
do (mediante políticas públicas de previdência, assistência e emprego, trabalho e renda) é o principal segmento ou ator social a estruturar e disponibilizar bens, serviços e renda à população. Embora sujeito à verificação empírica, é provável que em segundo lugar deva vir, em ordem de importância, não o Mercado privado de proteção social, mas sim as Famílias, cujo papel na tarefa de provisão de proteção social é ainda tão menosprezado (academicamente falando!) quanto difícil de aferir;

iii. Embora a função "proteção social" envolva e acione diversas estratégias combinadas de provisão entre pessoas e famílias, certamente não se esgotando nem se reduzindo à obtenção de renda monetária, essa fonte pode ser considerada o eixo central da proteção social num país como o Brasil, motivo pelo qual dimensionar e mapear a (des)proteção social segundo as considerações e restrições acima enunciadas parece ser um procedimento aceitável do ponto de vista do enfoque aqui pleiteado.

Do ponto de vista operacional, embora o ideal seja trabalhar com um conceito de PIA (população em idade ativa) que incorporasse, além da PEA (população ocupada e população desempregada involuntariamente), também o contingente de desempregados voluntários e de inativos involuntários (que não fazem parte do mercado de trabalho na condição de ofertantes ativos de trabalho), sabemos que as estatísticas existentes não permitem - senão mediante aproximações grosseiras - essa construção.

Por esse motivo, circunscrevemos o universo amostral à PEA entre $15 \mathrm{e}$ 59 anos e à População Idosa de 60 anos ou mais. ${ }^{11}$ Embora seja preciso verificar as condições de acesso da população idosa aos programas previdenciários e assistenciais de transferência e garantia de renda, é importante ressaltar que o foco principal se concentra aqui sobre a PEA acima definida, já que das condições de inserção no mundo do trabalho e no arco de ação das políticas públicas deve derivar sua capacidade futura de proteção social, conforme Quadro 3.

Em linhas gerais, tomando-se os dados do Censo 2010, chegamos à seguinte situação de (des)proteção previdenciária no Brasil:

Por detrás desses números agregados, confirma-se movimento positivo de expansão da cobertura previdenciária, medida entre 2000 e 2010 pelo percentual de contribuintes ao RGPS (portanto, excluindo-se dos cálculos os militares e estatutários que contribuem para o RPPS), da ordem de $+12,6 \%$ para os empregados assalariados, $+12,1 \%$ para as trabalhadoras domésticas, $+20,4 \%$ para os autônomos por conta própria, e $+2,4 \%$ para os empregadores (IBGE, Censo 2010). Já quando se considera a população idosa de 60 anos ou mais, a taxa de proteção previdenciária sobe, entre 2000 e 2010 , de $80,8 \%$ para $83,9 \%$ entre os homens, e de 62,6\% para 77,6\% entre as mulheres (IBGE, Censo 2010). 
Quadro 3 - Compatibilização entre benefícios de garantia de renda e categorias de inativos e trabalhadores PNAD

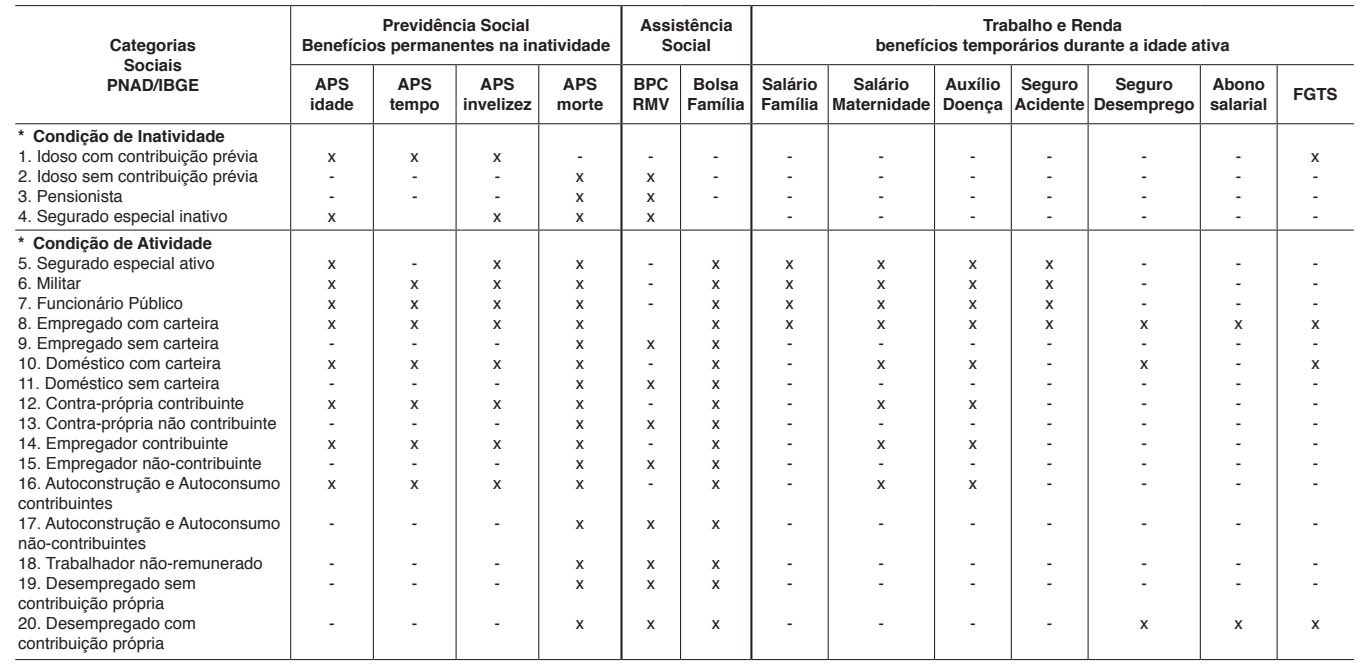

Fonte: PNAD/IBGE. Elaboração própria.

Figura 2 - Brasil - Proteção previdenciária da população ocupada (16 a 59 anos), segundo o Censo/IBGE 2010

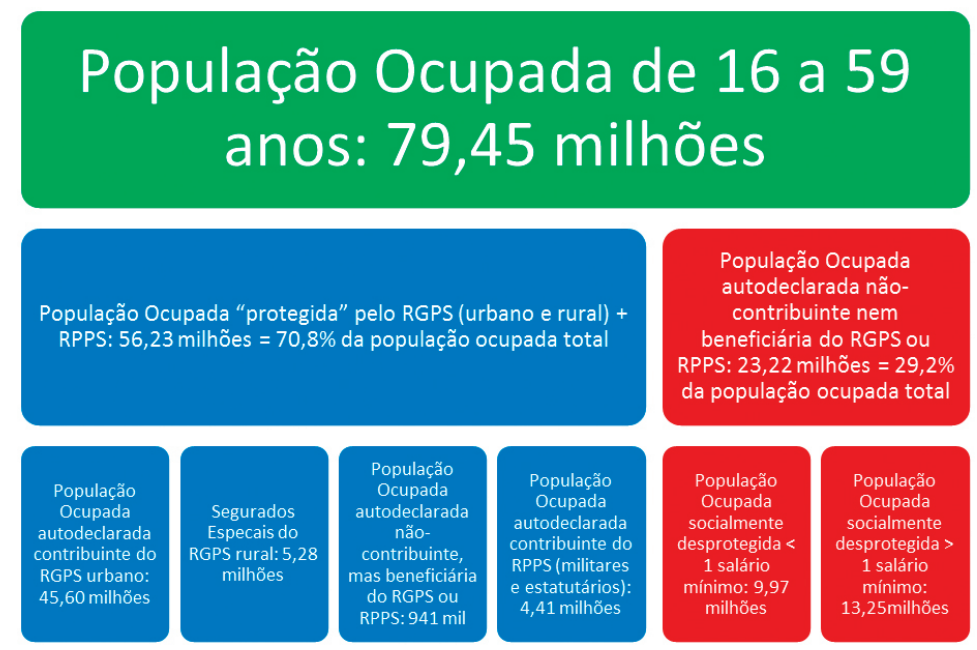

Elaboração: SPPS/MPS.

De posse das informações anteriores, tem-se - levando-se em conta apenas a população ocupada entre 16 e 59 anos - que apesar dos avanços recentes, ainda cerca de 30\% dela (tanto pelo Censo 2010, como pela PNAD 2012), isto é, algo equivalente a 25 milhões de trabalhadores e trabalhadoras, se autodeclararam sem qualquer tipo de cobertura laboral ou previdenciária. ${ }^{12}$

Esse vazio protetivo concentra-se nas categorias ocupacionais dos assalariados sem carteira (incluindo domésticas) e dos trabalhadores autônomos por conta própria, a grande maioria inserida em atividades precárias do setor 
terciário (comércio e serviços dos mais variados tipos) e na construção civil. Especialmente preocupante é o fato de esse contingente desprotegido situarse em faixa etária entre 25 e 39 anos de idade, justamente a faixa para a qual é mais importante uma vinculação previdenciária robusta, sob o risco de não se conseguir, ao longo do ciclo laboral futuro, construir trajetórias sustentáveis de inclusão pelo trabalho no mundo da proteção social regulada pelo Estado. Tal caracterização implica situação prospectiva de grave desproteção previdenciária, sobretudo para trabalhadores do mundo informal urbano, já que no caso dos trabalhadores rurais, o regime de previdência rural tem garantido ampliação até quase a universalização do acesso.

Dessa maneira, a tendência ao crescimento do número de idosos e de seu peso relativo na população torna necessário conceber, desde logo, políticas públicas destinadas a assegurar-lhes, no futuro, a sobrevivência, sob pena de a sociedade brasileira deparar, daqui a algumas décadas, com a existência de grande número de pessoas sem renda e sem condições de obtê-la pelo trabalho. Dessa forma, não são os direitos conquistados pelos trabalhadores brasileiros ao longo de décadas que precisam ser retalhados para que a atual estrutura do RGPS possa absorver seus beneficiários futuros, mas a forma de organização do RGPS (e, num sentido mais amplo, de todo o sistema brasileiro de proteção social) que precisa ser repensada para que se possa garantir proteção efetiva aos trabalhadores de hoje e aos idosos de amanhã (Cardoso Jr.; Magalhães, 2008).

A política social brasileira, comumente considerada, por analistas e setores conservadores da sociedade, como peso morto e elemento antagônico do crescimento econômico, pode e deve, na verdade, dentro da perspectiva ética e analítica aqui adotada, ser vista como parte integrante de um projeto de desenvolvimento de longo prazo para o país, pois coloca a população - particularmente aquela vinculada ou circundada pelo salário mínimo - no centro desta estratégia. ${ }^{13}$

\section{Padrões de desenvolvimento, mercado de trabalho}

e proteção social: a experiência brasileira entre as décadas liberal (1990) e desenvolvimentista (2000)

Olhando retrospectivamente, acreditamos que os eventos econômicos e políticos deflagrados no Brasil ao longo do último quarto de século XX tenham sido responsáveis pelo colapso do padrão histórico de desenvolvimento centrado na industrialização e comandado pelo Estado. O mesmo conjunto de eventos engendrou novo formato de desenvolvimento ao longo da década de 1990, calcado em concepção internacionalizante e liberal de progresso econômico e social, mas cujos resultados concretos, em pouco tempo, mostraram-se perversos do ponto de vista da dinâmica econômica - combinação de semiestagnação e financeirização da riqueza - e inadequados do ponto de vista da natureza e forma de funcionamento do seu mercado de trabalho, já que caracterizado por combinação de heterogeneidades e desigualdades de várias ordens. 
Na década liberal, as inserções setoriais típicas foram fruto mais da perda de dinamismo econômico da estrutura produtiva brasileira do que de um reordenamento dessa rumo a padrão de desenvolvimento de fato includente e sustentável. Adicionalmente, as inserções ocupacionais dominantes representaram, muito mais, estratégias de sobrevivência dos trabalhadores diante do colapso das alternativas de empregabilidade formal com proteção social, que livre escolha para alcançar ascensão profissional ou pessoal, ainda que muitas destas novas atividades autônomas possam redundar em certo prestígio ou mesmo em rendimentos médios mais elevados nas fases ascendentes dos ciclos (Castro; Dedecca, 1998).

A primeira década de 2000 , por outro lado, ensejara possibilidades históricas para nova fase de transição, cujos contornos - em delineamento - de um novo padrão de desenvolvimento, talvez ainda não permitam vislumbrar o seu sentido histórico geral. As diferenças entre ambos os períodos é um dos traços mais significativos do momento histórico de transição entre o modelo liberal parcialmente implementado na década de 1990 e essa fase atual de novas - mas ainda incertas - possibilidades de desenvolvimento na qual se encontra o país nos dias que correm.

Embora nos dez primeiros anos do novo milênio a agenda liberalizante de reformas trabalhistas tenha sido na prática contestada por resultados mais favoráveis da economia e do mercado de trabalho (tais como: crescimento da ocupação à frente do PIB, redução do desemprego aberto, aumento da formalização e dos rendimentos dos trabalhadores, melhora distributiva etc.), continuou presente o discurso liberalizante de parte dos empresários (sobretudo daqueles ligados ao comércio exterior e às finanças especulativas), bem como de parte de integrantes do governo e de membros do congresso.

\section{A reestruturação do trabalho na primeira década de 2000}

Mas em linhas gerais, pode-se dizer que, a despeito da combinação adversa de câmbio e juros, que por sinal está na raiz das baixas taxas de crescimento do PIB durante praticamente todo o ciclo do Real, houve um miniciclo de crescimento nos anos recentes (2004 a 2010) cujas causas estão na origem do movimento de recuperação do emprego formal. ${ }^{14}$

Dentre tais fatores, parece conveniente destacar ao menos cinco deles, sem a pretensão de esgotar outras possibilidades. Senão, vejamos: i) aumento e desconcentração do gasto social; ii) aumento e diversificação do crédito interno; iii) aumento e diversificação do saldo exportador; iv) ampliação do regime tributário simplificado para microempresas e empresas de pequeno porte (SIMPLES); e v) maior eficácia das ações de intermediação de mão de obra e de fiscalização das relações e condições de trabalho nas empresas, foram fatores identificados como responsáveis principais pela trajetória de recuperação do emprego formal no período 2003/2013 no Brasil. ${ }^{15}$

O acima citado é especialmente importante porque não é demais lembrar que todos os fatores aqui considerados sofrem influência direta de políticas go- 
vernamentais, estando, portanto, sujeitas à ação permanente do Estado, daí a importância de projetos consequentes e duradouros de desenvolvimento para a estruturação, entre outras coisas, de relações de trabalho mais sustentáveis dos pontos de vista econômico e social.

\section{Considerações finais: barbárie ou civilização?}

Tal como demonstrado pela experiência brasileira do período 2003-2013, não apenas foi possível compatibilizar certa retomada de crescimento econômico com reestruturação geral do mercado de trabalho e manutenção da estabilidade monetária, como isso se deu sem que tivesse havido reforma profunda - mantra liberal - do padrão de regulação do trabalho ou da proteção social no país. Com isso, demonstramos a incompatibilidade intrínseca entre o modelo de estruturação do mercado de trabalho com proteção social historicamente constituído no Brasil e modelos de desenvolvimento de cunho liberal. Tal incompatibilidade se dá, fundamentalmente, pela inadequação que se estabelece entre a dinâmica econômica de tipo liberal e a natureza heterogênea e desigual do mercado de trabalho brasileiro. Modelos de tipo liberal são, assim, inadequados a economias de tipo periférico-tardias como a brasileira, e contraproducentes a mercados de trabalho delas derivados.

A questão de fundo é que desde a promulgação da CF-1988, há no Brasil, grosso modo, dois projetos políticos em disputa no debate corrente. De um lado, coloca-se novamente em pauta - por setores conservadores da sociedade, comunidades da política (partidos, sindicatos e outras agremiações) e da própria burocracia, além da mídia e empresariado - o caminho liberal, de orientação privatista, que havia vivenciado melhores dias na década de 1990.

De outro lado, embora raramente tenha tido força política suficiente no cenário nacional, permanece como possibilidade - defendida por setores do campo progressista, dentro e fora das estruturas de governo - a via da universalização integral da proteção social. Para tanto, dada a particular estrutura de desigualdades sociais e econômicas do país, não basta que os gastos sociais sejam redistributivos para se avançar na eficácia das políticas públicas; é preciso também que sua forma de financiamento possua alta dose de progressividade na tributação, sobretudo sobre o patrimônio e os fluxos de renda real e financeira da coletividade. Todavia, é preciso ter claro que as bases materiais e as condições políticas hoje vigentes para uma reforma tributária de tal monta estão ainda mui distantes das mínimas necessárias à sua consecução.

Não obstante, constatamos haver instrumentos de ação e capacidade operativa suficiente nos aparelhos de Estado hoje existentes no Brasil, para ativação econômica e laboral em prol de estratégia mais robusta e duradoura de desenvolvimento com inserção social pelo trabalho (Cardoso Jr., 2013a). Mas é justamente por isso que o esforço envolvido no enfrentamento da questão social brasileira não pode prescindir do Estado como ator central nos processos de mudança. Qualquer solução sustentável em longo prazo deverá passar por recomposição do protagonismo estatal em meio à vida social e econômica do país. 
Assim, os indícios levantados no texto apontam para a necessidade de uma agenda mais explícita, orgânica e sistêmica de desenvolvimento, ancorada nos seguintes vetores de transformação positiva:

- Recuperação e sustentação do crescimento econômico em bases mais sólidas e níveis mais elevados que os atuais;

- Reestruturação institucional do padrão de financiamento público em geral, e das políticas sociais em particular. Vale dizer: reforma tanto tributária como fiscal, que seja capaz de combinar progressividade na arrecadação com redistributividade nos gastos;

- Consolidação de mínimos civilizatórios para a regulação (estruturação e regulamentação) do mundo do trabalho;

- Promoção politicamente deliberada da distribuição funcional e pessoal da renda;

- Construção de novas institucionalidades na relação Estado/Sociedade para a promoção da cidadania ampla e para a consolidação democrática. Vale dizer: reforma ético-política nos sistemas de representação, participação e deliberação, com valorização da esfera pública e da cidadania em todos os níveis.

Esse conjunto de diretrizes estratégicas perfila-se, claramente, ao lado do debate político e acadêmico defendido por setores do campo progressista da sociedade brasileira, dentro e fora das estruturas de governo. No caso brasileiro, a via liberal parcialmente implementada ao longo da década de 1990 provocou, dentre outras, desarticulação produtiva, financeirização da riqueza, precarização do mercado de trabalho e desmonte do sistema de proteção social, então em formação. A via liberal, portanto, inviabiliza trajetória sustentada de homogeneização econômica e social no país, não podendo se constituir em alternativa crível aos desafios da contemporaneidade colocados ao Brasil já nesta segunda década de século XXI.

\section{Notas}

l E no momento em que este texto é finalizado, a cartada mais recente - na mesma direção conservadora e regressiva - é o anúncio da Agenda Brasil, um conjunto de medidas fiscalistas e liberalizantes, lançado pelo então presidente do Senado, o Sr. Renan Calheiros, em articulação estreita com o ministro da Fazenda, o Sr. Joaquim Levy, e amplo "apoio programático" da presidenta da República, a Sra. Dilma Rousseff. Para um diagnóstico crítico e questões propositivas em outra direção, ver Fundação Perseu Abramo (2015).

$2 \mathrm{O}$ economista Ricardo Bielschowsky (2014) fala em três frentes de expansão - mercado interno de consumo de massas, investimentos em infraestrutura e exportações de produtos agroindustriais e minerais - para caracterizar o modelo de desenvolvimento desde 2003 em curso no Brasil. 
3 De acordo com editorial da Fundação Perseu Abramo datado de 25 de março de 2015 , edição 258 do FPA Informa, "As atuais dificuldades observadas na economia brasileira abriram espaço para um ataque amplo e irrestrito por parte das hostes liberais, que reputam o momento atual ao fracasso das políticas econômicas desenhadas no primeiro governo Dilma Rousseff. Valendo-se de seu amplo apoio e espaço nos meios de comunicação, o ataque tem como objetivo desconstruir e eliminar qualquer resquício de política de desenvolvimento econômico ativo, tendo agora encontrado apoio no coração do governo federal com Joaquim Levy no comando da economia. A defesa do retorno do tripé macroeconômico em sua concepção menos flexível e mais estrita se contrapõe ao suposto abandono da política de metas inflacionárias e a flexibilização do tripé macro conduzido no primeiro governo Dilma, enquanto o ataque à Petrobras (que inclui debates sobre privatização e abertura do pré-sal para exploração por empresas estrangeiras) e ao Banco Nacional de Desenvolvimento Econômico e Social (BNDES) completam o quadro de desconstrução dos principais instrumentos utilizados para promover o desenvolvimento nacional nos últimos anos".

4 Sobre o padrão ou padrões de regulação do trabalho no Brasil, incluindo discussões sobre a inserção produtiva das pessoas no mundo do trabalho, há uma literatura ampla sobre o assunto. Em especial, ver Baltar e Krein (2013), que inclusive citam alguns dos estudos recentes mais importantes sobre o tema no país.

5 Esse duplo caráter manifesta-se, por exemplo, na relação entre a Previdência e os trabalhadores rurais. Por um lado, a previdência os trata como cidadãos de segunda classe. Por outro, o reconhecimento de sua condição de "portadores de direitos" com o piso previdenciário atrelado ao salário mínimo ampliou, simbólica e materialmente, seu grau de cidadania.

6 Ver, por exemplo, Neffa e Eymard-Duvernay (2008).

7 Muito embora nem todas as ocupações autônomas possam ser explicadas por força da ausência de demanda assalariada por trabalho, esse é o caso de certamente a grande maioria das situações ocupacionais nestas condições, fato que torna válido o argumento geral aqui apresentado.

8 Um estudo crítico sobre a gênese e a crise atual da sociedade fundada no trabalho assalariado pode ser visto em Castel (1998). Já sobre a montagem histórica e dilemas atuais do chamado Sistema Brasileiro de Proteção Social, ver Cardoso Jr. e Jaccoud (2005).

9 As esferas estatal e societal (ou pública não estatal) compõem juntas a dimensão propriamente pública da tarefa de proteção social de uma comunidade ou país, enquanto as esferas familiar e a de mercado formam a dimensão privada de um padrão de proteção social qualquer.

$10 \mathrm{E}$, mais recentemente, segurança particular.

11 Embora o ideal seja trabalhar com um conceito de PIA (população em idade ativa) que incorporasse, além da PEA (população ocupada e população desempregada involuntariamente), também o contingente de desempregados voluntários e de inativos involuntários (que não fazem parte do mercado de trabalho na condição de ofertantes ativos de trabalho), sabemos que as estatísticas existentes não permitem - senão por meio de aproximações grosseiras - essa construção.

12 As bases do IBGE não permitem a estimativa do contingente de pessoas que não contribuem e não são beneficiárias de aposentadoria e/ou pensão por morte, mas que mantém a qualidade de seguradas. 
13 A fundamentação empírica, mostrando como e em que medida os gastos sociais impactam positivamente o produto interno bruto, pode ser visto em IPEA (2010).

14 Para os interessados em se aprofundar no assunto, há outros trabalhos que procuraram descrever estatisticamente este fenômeno de formalização do emprego no Brasil. Em particular, ver IBGE (2005 e 2006); MTE (2005); Costanzi (2004); Ramos \& Ferreira (2006); Dedecca \& Rosandiski (2006).

$15 \mathrm{Um}$ exame algo mais completo de cada um desses fatores pode ser visto em Cardoso Jr. (2013a).

\section{Referências}

ANSILIERO, G. Censo 2010: um panorama da proteção previdenciária no Brasil. Informe de Previdência Social, Brasília, v.24, n.7, jul. 2013.

Inclusão previdenciária e mercado de trabalho no Brasil: evidências para o período 1992-2011. Informe de Previdência Social, Brasília, v.25, n.2, fev. 2013.

ANTUNES, R. Os sentidos do trabalho. São Paulo: Boitempo, 1999.

BALTAR, P. E.; KREIN, J. D. A retomada do desenvolvimento e a regulação do mercado de trabalho no Brasil. Cadernos CRH, Salvador, v.26, n.68, maio-ago. 2013.

BALTAR, P.; MATTOSO, E. Transformações estruturais e emprego nos anos 90. Ensaios FEE, Porto Alegre, v.18, n.1, 1997.

BIELSCHOWSKY, R. Estratégia de desenvolvimento e as três frentes de expansão no Brasil: um desenho conceitual. In: CALIXTRE, A.; BIANCARELLI, A.; CINTRA, M. A. M. (Org.) Presente e futuro do desenvolvimento brasileiro. Brasília: Ipea, 2014.

CARDOSO JUNIOR, J. C. Mundo do trabalho e (des)proteção social no Brasil: ensaios de interpretação da história recente. 2013. Tese (Doutorado) - Instituto de Economia, Universidade Estadual de Campinas. Campinas, 2013a.

. Mundo do trabalho e (des)proteção social no Brasil. Rio de Janeiro: Azougue Editorial, 2013b.

CARDOSO JUNIOR, J. C.; JACCOUD, L. Políticas sociais no Brasil: organização, abrangência e tensões da ação estatal. In: JACCOUD, L. (Org.) Questão social e politicas sociais no Brasil contemporâneo. Brasília: Ipea, 2005.

CARDOSO JUNIOR, J. C.; MAGALHÃES, H. J. Trabalho, previdência e proteção social no Brasil: bases para um plano de benefícios adequado à realidade nacional. In: FAGNANI, E.; HENRIQUES, W.; LÚCIO, C. G. Previdência Social: como incluir os excluídos. São Paulo: LTr, 2008.

CASTEL, R. As metamorfoses da questão social: uma crônica do salário. Petrópolis: Vozes, 1998.

CASTRO, N. A.; DEDECCA, C. S. A ocupação na América Latina: tempos mais duros. São Paulo; Rio de Janeiro: Alast, 1998.

COSTANZI, R. N. Evolução do emprego formal no Brasil (1985-2003) e implicações para as politicas públicas de geração de emprego e renda. Brasília: Ipea, 2004 (Texto para Discussão n.1039). 
DEDECCA, C. S.; ROSANDISKI, E. N. Recuperação econômica e a geração de empregos formais. Brasília: Centro de Gestão e Estudos Estratégicos, Ministério da Ciência e Tecnologia, Parcerias Estratégicas, Edição Especial (Análise da PNAD 2004), n.22, 2006.

ESPING-ANDERSEN, G. Los tres mundos del Estado del Bien-Estar. Valencia: Alfons el Magnamim, 1993.

Mulino, 2000.

I fondamenti sociali delle economie postindustriali. Bologna: Società Editrice il

FAGNANI, E.; FONSECA, A. (Org.) Politicas sociais, desenvolvimento e cidadania. São Paulo: Ed. Fundação Perseu Abramo, 2013.

FUNDAÇÃO PERSEU ABRAMO. Por um Brasil justo e democrático. Mudar para sair da crise. Alternativas para o Brasil voltar a crescer. São Paulo: Fundação Preseu Abramo, 2015. v.1.

GIAMBIAGI, F.; PORTO, C. (Org.) Propostas para o governo 2015-2018: agenda para um país próspero e competitivo. Rio de Janeiro: Elsevier - Campus, 2013.

IBGE. Pesquisa Nacional por Amostra de Domicílios: síntese de indicadores 2005. Rio de Janeiro: IBGE, PNAD 2005.

Pesquisa Mensal de Emprego: principais destaques da evolução do mercado de trabalho nas regiões metropolitanas abrangidas pela pesquisa (2003-2006). Rio de Janeiro: IBGE, PME 2006.

IPEA. Perspectivas da politica social no Brasil. Brasília: Ipea, 2010.

KREI, D.; CARDOSO JUNIOR, J. C.; BIAVASCHI, M.; TEIXEIRA, M. (Org.) Regulação do trabalho e instituições públicas. São Paulo: Ed. Fundação Perseu Abramo, 2013.

MINISTÉRIO DO TRABALHO E EMPREGO. Características do emprego formal: Rais 2005. Brasília: MTE, Rais 2005.

NEFFA, J. C.; EYMARD-DUVERNAY, F. Teorias económicas sobre el mercado de trabajo: analisis institucionalistas. Buenos Aires: Fondo de Cultura Económica, 2008.

POCHAMNN, M. Subdesenvolvimento e trabalho. São Paulo: LTr, 2013.

RAMOS, L.; FERREIRA, V. Padrões espacial e setorial da evolução da informalidade no período 1991-2005. Pesquisa e Planejamento Econômico, Ipea, Rio de Janeiro, v.36, n.3, 2006.

ROSANVAlLON, P. A crise do Estado-Providência. Goiânia: Ed. UFG; Brasília: Ed. $\mathrm{UnB}, 1997$.

A nova questão social: repensando o Estado-Providência. Brasília: Instituto Teotônio Vilela, 1998.

RESUMO - A primeira década do novo milênio, mormente o período 2003-2013, cumpriu - entre outras - função didática nos embates acadêmico e político brasileiros. Após praticamente 25 anos de dominância ideológica liberal e tentativas de implementação de diretrizes e soluções desregulamentadoras, privatistas e internacionalizantes, com resultados pífios ou nefastos sobre indicadores clássicos do comportamento macroeco- 
nômico e do mercado de trabalho nacional, houve em período recente a contestação empírica e teórica da alegada supremacia daquelas formulações. A fim de captar esse movimento, este texto busca contrapor o desempenho dos padrões de desenvolvimento liberal (década de 1990) e desenvolvimentista (primeira década de 2000) e os seus impactos sobre o mundo do trabalho e a proteção social previdenciária em cada um dos respectivos períodos. As diferenças entre ambos é um dos traços mais significativos do momento histórico de transição entre o modelo liberal parcialmente implementado na década de 1990 e essa fase atual de novas - mas ainda incertas - possibilidades de desenvolvimento na qual se encontra o país nos dias que correm.

PALAVRAS-CHAVES: Padrões de desenvolvimento, Mercado de trabalho, Proteção social, Liberalismo, Desenvolvimentismo, Brasil.

ABSTRACT - Among other things, the first decade of the new millennium, and particularly the period 2003-2013, achieved an educational purpose in Brazil's academic and politic debate. After almost 25 years of liberal ideological dominance and attempts to implement deregulation, privatization and internationalization policies and solutions (with negligible or adverse results on the classic indicators of macroeconomic performance and on the domestic labor market), there has recently been empirical and theoretical opposition to the alleged supremacy of those formulations. To capture this transition, the article compares the performance of liberal development (in the 1990s) with the "developmentalism" of the early 2000s, as well as their impacts on the realm of labor and on social welfare policies in each period. The differences between them are one of the most significant features of the historical transition between the partially-implemented liberal model of the 1990s and the country's current phase of new - but still uncertain - possibilities of development.

KEYWORDS: Development patterns, Labor market, Social protection, Liberalism, Developmentalism, Brazil.

José Celso Cardoso Junior é economista pela Faculdade de Economia, Administração e Contabilidade da Universidade de São Paulo (FEA/USP), com mestrado em Teoria Econômica e doutorado em Desenvolvimento (com especialização em Economia Social e do Trabalho), ambos pelo Instituto de Economia da Universidade Estadual de Campinas (IE/Unicamp). Desde 1996 é técnico de Planejamento e Pesquisa do Instituto de Pesquisa Econômica Aplicada (Ipea). @ - josecelso.cardoso@ipea.gov.br

I Instituto de Pesquisa Econômica Aplicada, Brasília/Distrito Federal, Brasil.

Recebido em 27.8.2015 e aceito em 11.9.2015. 
